\title{
What are the most effective techniques in changing obese individuals' physical activity self-efficacy and behaviour: a systematic review and meta-analysis
}

Ellinor K Olander ${ }^{1 *}$, Helen Fletcher ${ }^{1}$, Stefanie Williams ${ }^{1}$, Lou Atkinson ${ }^{1}$, Andrew Turner ${ }^{1}$ and David P French ${ }^{2}$

\begin{abstract}
Increasing self-efficacy is generally considered to be an important mediator of the effects of physical activity interventions. A previous review identified which behaviour change techniques (BCTs) were associated with increases in self-efficacy and physical activity for healthy non-obese adults. The aim of the current review was to identify which BCTs increase the self-efficacy and physical activity behaviour of obese adults. A systematic search identified 61 comparisons with obese adults reporting changes in self-efficacy towards engaging in physical activity following interventions. Of those comparisons, 42 also reported changes in physical activity behaviour. All intervention descriptions were coded using Michie et al's (2011) 40 item CALO-RE taxonomy of BCTs. Meta-analysis was conducted with moderator analyses to examine the association between whether or not each BCT was included in interventions, and size of changes in both self-efficacy and physical activity behaviour. Overall, a small effect of the interventions was found on self-efficacy $(d=0.23,95 \%$ confidence interval $(C)$ : $0.16-0.29, p<0.001)$ and a medium sized effect on physical activity behaviour $(d=0.50,95 \% \mathrm{Cl} 0.38-0.63, \mathrm{p}<0.001$ ). Four $\mathrm{BCT}$ s were significantly associated with positive changes in self-efficacy; 'action planning', 'time management', 'prompt self-monitoring of behavioural outcome' and 'plan social support/social change'. These latter two BCTs were also associated with positive changes in physical activity. An additional 19 BCTs were associated with positive changes in physical activity. The largest effects for physical activity were found where interventions contained 'teach to use prompts/cues', 'prompt practice' or 'prompt rewards contingent on effort or progress towards behaviour'. Overall, a non-significant relationship was found between change in self-efficacy and change in physical activity (Spearman's Rho $=-0.18 p=0.72$ ). In summary, the majority of techniques increased physical activity behaviour, without having discernible effects on self-efficacy. Only two BCTs were associated with positive changes in both physical activity self-efficacy and behaviour. This is in contrast to the earlier review which found a strong relationship between changes in physical activity self-efficacy and behaviour. Mechanisms other than self-efficacy may be more important for increasing the physical activity of obese individuals compared with non-obese individuals.
\end{abstract}

Keywords: Obesity, Self-efficacy, Physical activity, Behaviour change techniques

\footnotetext{
*Correspondence: ellinor.olander@coventry.ac.uk

'Applied Research Centre in Health and Lifestyle Interventions, Coventry University, Priory Street, Coventry CV1 5FB, UK

Full list of author information is available at the end of the article
} 


\section{Introduction}

Approximately 200 million men and 300 million women are currently obese worldwide [1], with prevalence increasing [2]. Obesity is associated with numerous health risks, including an elevated risk of diabetes [3], heart failure [4], and depression [5]. Consequently, it has been argued that obesity is now the second largest modifiable cause of preventable death [6]. To alleviate these health risks in obese adults, physical activity has been recommended [7].

Self-efficacy has been identified as a key determinant in increasing physical activity [8]. Self-efficacy is the belief that one has the ability to successfully engage in a specific behaviour, such as physical activity. Findings from experimental studies show that self-efficacy can mediate the effects of interventions on physical activity behaviour. For example, Darker and colleagues found that the participants who showed largest changes in walking self-efficacy following a single session walking intervention were also the ones who showed the largest increases in objectively assessed walking behaviour [9].

Given that self-efficacy for physical activity is an important determinant of physical activity, it becomes essential to identify the best methods of increasing self-efficacy for physical activity. A recent systematic review and metaanalysis identified which behaviour change techniques (BCTs) were associated with an increase in self-efficacy for physical activity and physical activity behaviour [10,11]. This review identified intervention studies targeting physical activity in 'healthy' adults that also measured selfefficacy for physical activity. All interventions were coded using a standardised taxonomy of behaviour change techniques [12] to assess which BCTs were present in each intervention. Small significant effects of interventions were found on self-efficacy $(d=0.16,95 \%$ confidence interval $[\mathrm{CI}]: 0.08-0.24, \mathrm{P}<.001)$ and physical activity $(d=0.21$, 95\% CI 0.11-0.31, $\mathrm{P}<0.001)$ and a significant large relationship between change in self-efficacy and change in physical activity behaviour was observed (Spearman's Rho $=0.69, \mathrm{p}<0.001)$ [10]. Three BCTs were associated with significant increases in both self-efficacy and physical activity behaviour; 'action planning,' 'reinforcing effort or progress towards behaviour' and 'provide instruction'. These findings are important as they provide researchers as well as practitioners with information regarding which intervention components may increase intervention efficacy [12].

However, the Williams and French [10] review only included 'healthy' (i.e. participant groups not characterised by a common diagnosis) and non-obese individuals $(\mathrm{BMI}<30)$ and it is uncertain if the same BCTs would be effective in increasing self-efficacy and physical activity behaviour in other populations. For example, another recent systematic review did not find any effective behaviour change techniques for changing physical activity behaviour in obese adults with obesity-related comorbidities or risk factors [13], suggesting that different BCTs may be effective at changing physical activity in different populations.

The aim of the present review was to identify which behaviour change techniques were associated with increases or decreases in self-efficacy for physical activity and physical activity behaviour in obese adults. A secondary aim of this review was to assess if the same techniques which were effective at changing self-efficacy were also effective at changing physical activity in this population.

\section{Methods}

\section{Inclusion criteria}

Eligible study designs included randomised controlled trials, non-randomised controlled trials, quasi-experimental studies or studies with pre-post design. Studies which used qualitative methods, a correlational design or used selfefficacy as a predictor only were excluded. Only English language reports were included for pragmatic reasons.

To be included in the review, the sample had to have a mean BMI of 30 or above (i.e. obese) and a mean of 18 years or more.

One of the intervention aims had to be to increase physical activity. Hence interventions which aimed to alter physical activity and eating behaviour were included. Interventions that focused on sport performance or were laboratory-based and did not aim to increase frequency or duration of physical activity behaviour were excluded.

All included studies had to report an experimentally induced change in physical activity self-efficacy. That is, physical activity self-efficacy had to be measured pre and post intervention when there was no comparison group or be measured for both intervention and comparison groups at least once following the end of the intervention. Where identified studies otherwise satisfied the inclusion criteria, but the report lacked this self-efficacy data the corresponding author was contacted for additional information.

\section{Search method}

The electronic databases PsycInfo (1966-2011) and Scopus (1960-2011) were searched using a broad search strategy including self-efficacy, physical activity and trial terms (see Appendix 1). An initial search was conducted in June 2011 and updated in November 2011. All searches and eligibility assessment were conducted by the first and fourth author, through first screening of abstracts and subsequent examination of full texts where appropriate. All included papers were also subjected to forward and backward searches. See Figure 1 for a flowchart illustrating the review process. 


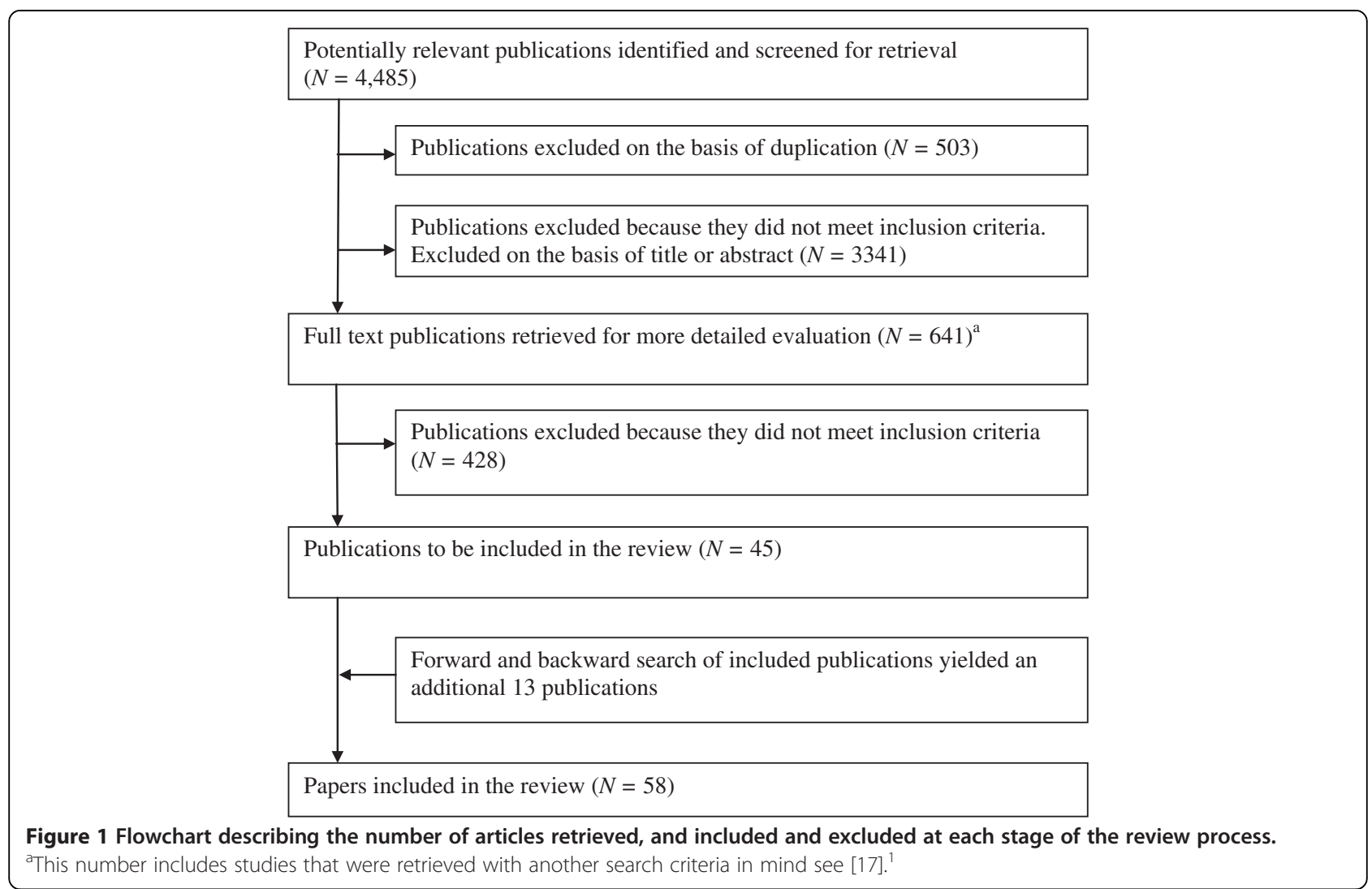

\section{Data extraction}

Relevant papers were entered into EndNote X3, and study and intervention characteristics as well as sample sizes, means and standard deviations were extracted by the first author. Effect size estimates (standardised mean difference or Cohen's $d$ [14]), were calculated by the same author. All intervention descriptions were double coded for behaviour change techniques using the Coventry Aberdeen LOndon REfined (CALO-RE) taxonomy [12] by the first author and either the second or third author. The CALO-RE taxonomy is an updated and expanded version of the taxonomy developed by Abraham and Michie [15], and was developed to identify BCTs used in physical activity or healthy eating interventions. Interrater reliability as assessed by kappa, corrected for chance agreement, was 0.68 . This was calculated based on double coding of $23 \%$ of the intervention descriptions. Any disagreements between coders were resolved by discussion.

\section{Data analysis}

The effect sizes and meta-analyses for self-efficacy and physical activity were conducted separately. The metaanalytic calculations were performed using Schwarzer's (1987) Meta computer program [16], using a randomeffects model. When studies reported more than one experimental group, each experimental group was compared to the control group to yield effect size estimates. When a study reported data at several time points post intervention, the one most immediately after the intervention end was used as this is when the largest effect attributable to the intervention should have occurred. When a comparison group had a mean BMI below 30, baseline and post intervention scores for the intervention group (with a BMI above 30) were analysed as a pre-post design. Heterogeneity was assessed using the $Q$ coefficient. Moderator analyses investigated causes of heterogeneity, by comparing effect size estimates for groups of studies characterised by the presence or not of each behaviour change technique. Pairwise $\mathrm{Z}$ tests were conducted for each intervention technique to assess whether two groups had significantly different effect size estimates.

Spearman's Rho correlation coefficient was used to assess whether change in self-efficacy was associated with change in physical activity behaviour. For each BCT the effect size estimate where the technique was not present was subtracted from the effect size estimate where the technique was present to calculate a difference score for both self-efficacy and physical activity behaviour. These differences were then correlated across BCTs.

\section{Results}

The electronic search identified 4485 potential publications, of which 641 were retrieved for full text examination (some of these were retrieved with another search 
criteria in mind see [17]) $)^{1}$. Of those, data from 45 publications were included in the review. Forward and backward searches identified another 13 eligible publications (see Figure 1). A total of 61 comparisons (58 publications) were included for the self-efficacy analyses [18-75] and 42 comparisons (39 publications either linked to or the same as the original 58 publications) were included for the physical activity behaviour analyses $[18,19,24$ $26,28,35,36,38,40-43,45,47-50,52,54,56-59,61,63,65-68,70$, $71,73,75-81]$.

\section{Study characteristics}

The mean number of participants in the comparisons included in the self-efficacy analysis was 181 and 170 (range 21 to 860 for both analyses) for the studies only included in the physical activity behaviour analysis. Overall, 25 of the comparisons employed a controlled design, and 36 used a pre-post design (see Table 1). Barrier self-efficacy was most commonly assessed (77\% of all comparisons), with task self-efficacy assessed in 14\% of comparisons (see Table 1).

\section{Intervention characteristics}

Despite assessing self-efficacy, an explicit theoretical basis was mentioned for only two thirds of studies, with the most frequent being Social Cognitive Theory [82] (see Table 2). Interventions were delivered by a wide variety of people and in a variety of locations, but most commonly a health and fitness professional in a fitness centre or gym (see Table 2). Almost half of interventions had an explicit focus on weight loss or weight maintenance, and two thirds focused on healthy eating in addition to physical activity (see Table 2 ).

A mean of $10.5(\mathrm{SD}=6.4) \mathrm{BCTs}$ were identified for the 61 comparisons included in the self-efficacy analysis. The control group interventions had a mean of 0.8 BCTs $(\mathrm{SD}=1.5)$. A mean of $9.0(\mathrm{SD}=5.3)$ BCTs were identified for the 42 comparisons included in the physical activity behaviour analysis. The control group interventions had a mean of $0.7 \mathrm{BCTs}(\mathrm{SD}=1.5)$. The most commonly used BCTs in both analyses were 'goal setting (behaviour), 'prompt self-monitoring of behaviour' and 'prompt practice' (see Table 3).

\section{Changes in self-efficacy}

For the analysis of changes in self-efficacy, 61 comparisons were included, indicating a small effect of the interventions on self-efficacy $(d=0.23,95 \%$ confidence interval $(\mathrm{CI})$ : $0.16-0.29, \mathrm{p}<0.001)$. Fail-safe $\mathrm{N}(\mathrm{p}=0.05)$ was large: it would require an additional 2113 studies showing a zero effect not included in the present analysis for the relationship between interventions and selfefficacy to become statistically non significant [83]. A forest plot showing self-efficacy effect sizes with 95\% CI for each study ordered by research design is given in Figure 2. A greater variability in effect size estimates existed than could be explained by random sampling error alone $(Q=129.27, \mathrm{p}<0.001)$. The amount of variance attributable to sampling error was $58.29 \%$. Effect sizes for self-efficacy ranged from $d=-0.44$ [35] to $d=0.72[39,41]$.

In total, 28 moderator analyses were conducted to investigate differences in self-efficacy according to presence or absence of BCTs (see Table 4). Moderator analyses were not conducted for those $\mathrm{BCT}$ s that were not coded as present in any (BCT: $3,4,14,30,31,32,34$ and 40, as listed in Table 3 ) or in only one intervention group (BCT: 11, 18, 24 and 39, as listed in Table 3).

Four BCTs were significantly associated with higher selfefficacy effect sizes when present (all; $\mathrm{p}<.05$ ); 'action planning,' 'prompt self-monitoring of behavioural outcome', 'plan social support/social change' and 'time management'. Two BCTs were significantly associated with lower selfefficacy effect sizes when present 'set graded tasks' and 'prompting generalisation of a target behaviour'. The presence or absence of the remaining 23 behaviour change techniques was not significantly associated with selfefficacy effect size estimates (see Table 4).

\section{Changes in physical activity}

For the analysis of changes in physical activity behaviour, 42 comparisons were included indicating a significant medium effect of the interventions on physical activity behaviour $(d=0.50,95 \%$ CI $0.38-0.63, \mathrm{p}<0.001)$. Fail-safe N $(\mathrm{p}=0.05)$ was large: it would require an additional 5789 studies showing a zero effect not included in the present analysis for the relationship between interventions and physical activity to become statistically non significant [83]. A forest plot showing physical activity effect sizes with $95 \%$ CI for each study ordered by research design is given in Figure 3. A greater variability in effect size estimates existed than could be explained by random sampling error alone $(Q=293.86, \mathrm{p}<0.001)$. The amount of variance explained by sampling error was notably lower than was the case for self-efficacy at $31.75 \%$. Effect sizes ranged from $d=-0.47$ [50] to $d=1.2$ [66].

In total, 27 moderator analyses were conducted to investigate differences in physical activity behaviour according to presence or absence of BCTs. Moderator analyses were not conducted for those BCTs which were not coded as present in any (BCT: 3, 4, 14, 27, 30, 31, 32, 34 and 40 as listed in Table 3 ) or in only one intervention group (BCT: 11, 18, 24 and 39 as listed in Table 3).

Twenty-one BCTs were significantly associated with higher physical activity behaviour effect sizes when present, and only 'prompting generalisation of a target behaviour' was associated with a lower effect size estimate when present (see Table 4). The greatest difference in effect size occurred when the following techniques 
Table 1 Summary of the participant and study characteristics of included publications

\begin{tabular}{|c|c|c|}
\hline Participant characteristics $^{\mathrm{a}}$ & $\begin{array}{l}\text { Mean (standard deviation) for } \\
\text { self-efficacy analysis }\end{array}$ & $\begin{array}{l}\text { Mean (standard deviation) for physical activity } \\
\text { analysis }\end{array}$ \\
\hline Mean age in years of participants (range $28-77$ years) ${ }^{a}$ & $49.1(9.5)$ & $50.0(10.0)$ \\
\hline Mean BMI of participants (range $30-42)^{a, b}$ & $34.5(3.7)$ & $34.5(3.9)$ \\
\hline Mean percentage of females per study (range 0-100\%)a, b & $79.2 \%(29.7)$ & $73.1 \%(32.7)$ \\
\hline $\begin{array}{l}\text { Mean percentage of white participants per study (range } \\
0-100 \%)^{a, b}\end{array}$ & $59.6 \%(31.3)$ & $59.0 \%(36.3)$ \\
\hline Study design ${ }^{c}$ & $\begin{array}{l}\text { Frequencies for self-efficacy } \\
\text { analysis }\end{array}$ & Frequencies for physical activity analysis \\
\hline Controlled trials & 25 & 18 \\
\hline Pre-post design & 36 & 24 \\
\hline Type of self-efficacy measured ${ }^{d}$ & $\begin{array}{l}\text { Frequencies for self-efficacy } \\
\text { analysis }\end{array}$ & Frequencies for physical activity analysis \\
\hline Task self-efficacy & 9 & N/A \\
\hline Barrier self-efficacy & 47 & N/A \\
\hline Combined barrier and task self-efficacy & 1 & N/A \\
\hline Other/unclear & 3 & N/A \\
\hline
\end{tabular}

a Data on age, exact BMI, gender and ethnicity was not provided by all studies.

b This is the range for both the self-efficacy and physical activity studies.

' This data is for the statistical analyses conducted, some of the studies were RCT's but were analysed as pre-post studies.

d One study measured perceived behavioural control, not self-efficacy [68].

were present; 'teach to use prompts/cues', 'prompt practice' and 'prompt rewards contingent on effort or progress towards behaviour'. There were no significant differences in physical activity effect size estimates between interventions that included the remaining four BCTs and interventions that did not.

\section{Comparison of techniques associated with self-efficacy and physical activity}

A negative non-significant relationship was found between the change in self-efficacy and the change in physical activity for the 27 behaviour change techniques included in at least two interventions (Spearman's Rho $=-0.18$ $\mathrm{p}=0.72$ ). Of the 27 techniques included in both moderator analyses, only six did not show an increase in effect size when the technique was present for physical activity and of these two were associated with an increase in selfefficacy.

\section{Discussion}

This meta-analysis of physical activity interventions for obese adults found a small $(d=0.23)$ but significant effect of interventions on self-efficacy and a significant effect of interventions on physical activity behaviour $(d=0.50)$ of medium size. The moderator analyses identified four behaviour change techniques that were associated with a higher self-efficacy effect size estimate. Only two of these techniques; 'prompt self-monitoring of behavioural out- come' and 'plan social support/social change', were also associated with higher effect size estimate for physical activity behaviour. In addition, two techniques were found to be associated with a lower self-efficacy effect size estimates; 'set graded tasks' and 'prompting generalisation of a target behaviour'. The latter technique was also associated with a lower physical activity behaviour effect size estimate. For physical activity behaviour, 21 techniques in total were found to be associated with a higher effect size estimate. The largest effects were found for 'teach to use prompts/cues,' 'prompt practice' and 'prompt rewards contingent on effort or progress towards behaviour'. The association between the changes in self-efficacy and physical activity behaviour was small and not statistically significant (Spearman's Rho $=-0.18$ ).

\section{Strengths and limitations}

There are several strengths of this systematic review and meta-analysis. Firstly, we conducted a systematic review using broad search terms to increase the probability of identifying all eligible publications, and which yielded a good sized $(k=61)$ evidence base. Secondly, we used the same methods and analysis as a previous review [10], allowing for a comparison of effective BCTs between 'healthy' non-obese adults and obese adults. Thirdly, intervention contents were reliably coded using a standardised taxonomy for BCT's [12].

There are a few limitations associated with this review. There were numerous BCTs examined as independent 
Table 2 Summary of intervention characteristics of included publications for self-efficacy analysis Intervention characteristics Frequencies for self-efficacy analysis $(k=61)$ analysis $(k=42)$

Theoretical basis

Theoretical basis explicitly mentioned

Some theory mentioned

No theoretical basis explicitly mentioned

Social Cognitive Theory

Transtheoretical Model

Self-determination Theory

Other/Unclear

Type of activities

Individual

Group

Both individual and group

Intervention focus

Exercise (e.g. aerobics class, gym, jogging)

Delivered by

'Facilitator'/'Interventionist'

Health and fitness professional

Nurse or GP

Peers/lay expert

Researcher

Not stated

Other (including coach, dietician, instructor)

Setting

By internet/post/telephone

Church

College/University

Community Centre

Fitness centre/gym

GP Surgery/Hospital

Participants home

Workplace

Unclear/Other

Delivery mode

Counselling session 
Table 3 Frequencies of behaviour change techniques that were used in the interventions

\begin{tabular}{|c|c|c|c|c|}
\hline \multirow[t]{2}{*}{ Technique } & \multicolumn{2}{|c|}{ Self-efficacy ( $k=61$ comparisons) } & \multicolumn{2}{|c|}{ Physical activity ( $k=42$ comparisons) } \\
\hline & $\mathbf{N}$ & $\%$ & $\mathrm{~N}$ & $\%$ \\
\hline 5. Goal setting (behaviour) & 48 & $78.7 \%$ & 34 & $81 \%$ \\
\hline 16. Prompt self-monitoring of behaviour & 45 & $73.8 \%$ & 29 & $69 \%$ \\
\hline 26. Prompt practice & 42 & $68.9 \%$ & 27 & $64.3 \%$ \\
\hline 8. Barrier Identification/Problem solving & 39 & $63.9 \%$ & 24 & $57.1 \%$ \\
\hline 35. Relapse prevention/coping planning & 38 & $62.3 \%$ & 25 & $59.5 \%$ \\
\hline 21. Provide instruction on how to perform the behaviour & 37 & $60.7 \%$ & 22 & $52.4 \%$ \\
\hline 29. Plan social support/social change & 34 & $55.7 \%$ & 21 & $50 \%$ \\
\hline 1. Provide information on consequences of behaviour in general & 33 & $54.1 \%$ & 20 & $47.6 \%$ \\
\hline 2. Provide information on consequences of behaviour for the individual & 30 & $49.2 \%$ & 16 & $38.1 \%$ \\
\hline 9. Set graded tasks & 28 & $45.9 \%$ & 17 & $40.5 \%$ \\
\hline 10. Prompt review of behavioural goals & 26 & $42.6 \%$ & 14 & $33.3 \%$ \\
\hline 38. Time management & 26 & $42.6 \%$ & 16 & $38.1 \%$ \\
\hline 6. Goal Setting (outcome) & 23 & $37.7 \%$ & 12 & $28.6 \%$ \\
\hline 12. Prompt rewards contingent on effort or progress towards behaviour & 23 & $37.7 \%$ & 11 & $26.2 \%$ \\
\hline 19. Provide feedback on performance & 23 & $37.7 \%$ & 11 & $26.2 \%$ \\
\hline 33. Prompt self-talk & 22 & $36.1 \%$ & 11 & $26.2 \%$ \\
\hline 36. Stress Management/emotional control training & 22 & $36.1 \%$ & 12 & $28.6 \%$ \\
\hline 13. Provide rewards contingent on successful behaviour & 19 & $31.1 \%$ & 9 & $21.4 \%$ \\
\hline 23. Teach to use prompts/cues & 18 & $29.5 \%$ & 7 & $16.7 \%$ \\
\hline 25. Agree behavioural contract & 17 & $27.9 \%$ & 5 & $11.9 \%$ \\
\hline 7. Action planning & 12 & $19.7 \%$ & 7 & $16.7 \%$ \\
\hline 22. Model/demonstrate the behaviour & 10 & $16.4 \%$ & 9 & $21.4 \%$ \\
\hline 28. Facilitate social comparison & 7 & $11.5 \%$ & 6 & $14.3 \%$ \\
\hline 20. Provide information on where and when to perform the behaviour & 4 & $6.6 \%$ & 4 & $9.5 \%$ \\
\hline 37. Motivational interviewing & 4 & $6.6 \%$ & 3 & $7.1 \%$ \\
\hline 15. Prompting generalisation of a target behaviour & 3 & $4.9 \%$ & 3 & $7.1 \%$ \\
\hline 17. Prompt self-monitoring of behavioural outcome & 2 & $3.3 \%$ & 2 & $4.8 \%$ \\
\hline 27. Use of follow up prompts & 2 & $3.3 \%$ & 1 & $2.4 \%$ \\
\hline 11. Prompt review of outcome goals & 1 & $1.6 \%$ & 1 & $2.4 \%$ \\
\hline 18. Prompting focus on past success & 1 & $1.6 \%$ & 0 & $0 \%$ \\
\hline 24. Environmental restructuring & 1 & $1.6 \%$ & 0 & $0 \%$ \\
\hline 39. General communication skills training & 1 & $1.6 \%$ & 1 & $2.4 \%$ \\
\hline 3. Provide information about others' approval & 0 & $0 \%$ & 0 & $0 \%$ \\
\hline 4. Provide normative information about others' behaviour & 0 & $0 \%$ & 0 & $0 \%$ \\
\hline 14. Shaping & 0 & $0 \%$ & 0 & $0 \%$ \\
\hline 30. Prompt identification as role model/position advocate & 0 & $0 \%$ & 0 & $0 \%$ \\
\hline 31. Prompt anticipated regret & 0 & $0 \%$ & 0 & $0 \%$ \\
\hline 32. Fear arousal & 0 & $0 \%$ & 0 & $0 \%$ \\
\hline 34. Prompt use of imagery & 0 & $0 \%$ & 0 & $0 \%$ \\
\hline 40. Stimulate anticipation of future rewards & 0 & $0 \%$ & 0 & $0 \%$ \\
\hline
\end{tabular}




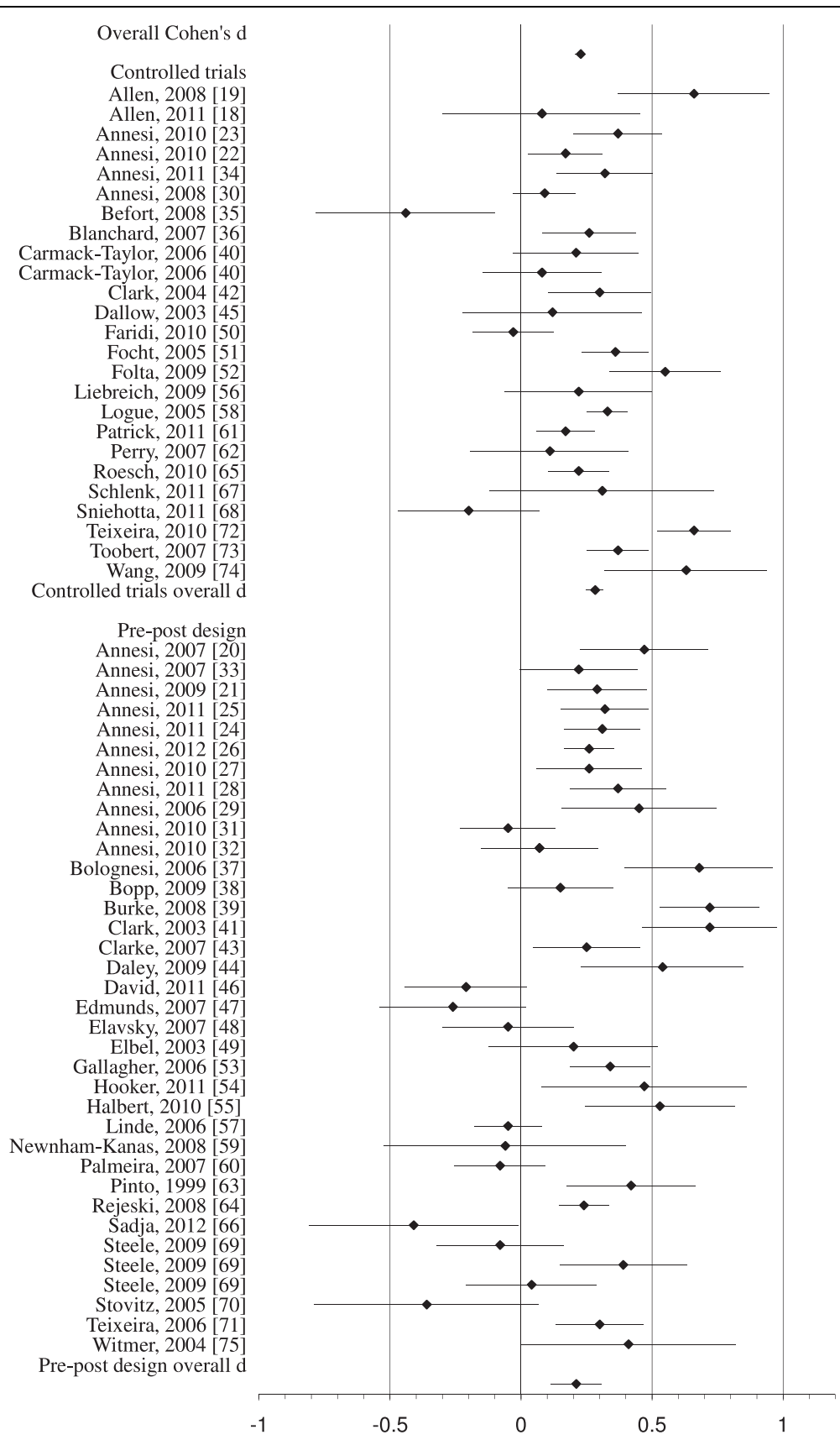

Figure 2 Forest plot showing self-efficacy effect sizes with $95 \% \mathrm{Cl}$ for each study, with studies ordered by reserach design.

moderators leading to a large number of comparisons conducted. Thus, it is entirely possible that some of the significant effects were identified due to chance alone: there was an inflation of risk of type 1 error. The analyses were based on identifying associations between interventions which contained specific BCTs and two outcome variables. It is entirely possible that some of these associations identified are due to confounding variables, i.e. characteristics of population, intervention other than BCTs or type of self-efficacy measured ${ }^{2}$. The current analyses also only examine the associations with presence or absence of $\mathrm{BCTs}$, and do not take into account quality of BCT delivery or combinations of techniques. Interventions are rarely developed to test single factors, thus combinations of techniques were common and individual techniques cannot be tested. Moreover, it is possible that some techniques are more common to cluster than others, thus our findings should not be taken to mean that these techniques has these effects when used on their own. Unfortunately, our study sample is too small for reliably testing the combinations of 
Table 4 Comparison between self-efficacy and physical activity behaviour, according to whether specific techniques are present in the physical activity intervention and when the technique is not present

\begin{tabular}{|c|c|c|c|c|c|c|c|c|c|c|c|c|c|c|}
\hline \multirow[t]{3}{*}{ Technique } & \multicolumn{7}{|c|}{ Self-efficacy } & \multicolumn{7}{|c|}{ Physical activity } \\
\hline & \multicolumn{3}{|c|}{ Present } & \multicolumn{4}{|c|}{ Not present } & \multicolumn{3}{|c|}{ Present } & \multicolumn{4}{|c|}{ Not present } \\
\hline & $n$ & $k$ & $d$ & $n$ & $k$ & $d$ & $z$ & $n$ & $k$ & $d$ & $n$ & $k$ & $d$ & $z$ \\
\hline 1. Provide information on consequences of behaviour in general & 5462 & 30 & .174 & 4888 & 31 & .206 & .80 & 3721 & 19 & .601 & 3893 & 23 & .437 & $3.45^{* * *}$ \\
\hline $\begin{array}{l}\text { 2. Provide information on consequences of behaviour for the } \\
\text { individual }\end{array}$ & 4862 & 24 & .244 & 5488 & 37 & .213 & .78 & 2544 & 10 & .641 & 5070 & 32 & .501 & $2.77^{* *}$ \\
\hline 5. Goal setting (behaviour) & 7768 & 43 & .212 & 2582 & 18 & .268 & 1.22 & 5447 & 29 & .624 & 2167 & 13 & .346 & $5.31^{* * *}$ \\
\hline 6. Goal Setting (outcome) & 5514 & 21 & .235 & 4836 & 40 & .216 & .48 & 3575 & 10 & .751 & 4039 & 32 & .448 & $6.31^{* * *}$ \\
\hline 7. Action planning & 1563 & 12 & .322 & 8787 & 49 & .208 & $2.05^{*}$ & 1026 & 7 & .613 & 6588 & 35 & .520 & 1.33 \\
\hline 8. Barrier Identification/Problem solving & 6496 & 38 & .247 & 3404 & 23 & .189 & 1.40 & 4617 & 23 & .678 & 2997 & 19 & .349 & $6.78^{* * *}$ \\
\hline 9. Set graded tasks & 5833 & 26 & .167 & 4517 & 35 & .287 & $3.03^{* *}$ & 4315 & 17 & .716 & 3299 & 25 & .392 & $6.74^{* * *}$ \\
\hline 10. Prompt review of behavioural goals & 5610 & 26 & .245 & 4740 & 35 & .212 & 0.83 & 3596 & 14 & .628 & 4018 & 28 & .494 & $2.80^{* *}$ \\
\hline $\begin{array}{l}\text { 12. Prompt rewards contingent on effort or progress towards } \\
\text { behaviour }\end{array}$ & 4312 & 23 & .236 & 6038 & 38 & .223 & 0.32 & 2407 & 11 & .830 & 5207 & 31 & .429 & $7.74^{* * *}$ \\
\hline 13. Provide rewards contingent on successful behaviour & 4420 & 19 & .249 & 5930 & 42 & .215 & 0.85 & 2624 & 9 & .682 & 4990 & 33 & .494 & $3.74^{* * *}$ \\
\hline 15. Prompting generalisation of a target behaviour & 598 & 3 & 0.05 & 9752 & 58 & .237 & $2.20^{*}$ & 598 & 3 & .380 & 7016 & 39 & .552 & $1.96^{*}$ \\
\hline 16. Prompt self-monitoring of behaviour & 8552 & 43 & .216 & 1798 & 18 & .256 & 0.76 & 6294 & 29 & .600 & 1320 & 13 & .279 & $5.16^{* * *}$ \\
\hline 17. Prompt self-monitoring of behavioural outcome & 466 & 2 & .468 & 9884 & 59 & .217 & $2.59^{* *}$ & 497 & 2 & .804 & 7117 & 40 & .524 & $2.85^{* *}$ \\
\hline 19. Provide feedback on performance & 4795 & 23 & .244 & 5555 & 38 & .214 & 0.75 & 2804 & 11 & .637 & 4810 & 31 & .497 & $2.81^{* *}$ \\
\hline $\begin{array}{l}\text { 20. Provide information on where and when to perform the } \\
\text { behaviour }\end{array}$ & 787 & 3 & .309 & 9563 & 58 & .224 & 1.13 & 815 & 3 & .488 & 6799 & 39 & .544 & 0.73 \\
\hline 21. Provide instruction on how to perform the behaviour & 5346 & 31 & .241 & 5004 & 30 & .213 & 0.70 & 3583 & 19 & .676 & 4031 & 23 & .430 & $5.15^{* * *}$ \\
\hline 22. Model/demonstrate the behaviour & 881 & 10 & .155 & 9469 & 51 & .235 & 1.12 & 841 & 9 & .797 & 6773 & 33 & .511 & $3.70^{* * *}$ \\
\hline 23. Teach to use prompts/cues & 3975 & 18 & .236 & 6375 & 43 & .221 & 0.37 & 2112 & 7 & .949 & 5502 & 35 & .433 & $9.50^{* * *}$ \\
\hline 25. Agree behavioural contract & 3782 & 17 & .262 & 6568 & 44 & .205 & 1.38 & 1823 & 5 & .880 & 5791 & 37 & .480 & $7.03^{* * *}$ \\
\hline 26. Prompt practice & 5713 & 35 & .231 & 4637 & 26 & .220 & 0.28 & 4071 & 25 & .725 & 3543 & 17 & .283 & $9.30^{* * *}$ \\
\hline 27. Use of follow up prompts & 334 & 2 & .338 & 10016 & 59 & .223 & 1.01 & $\begin{array}{l}\text { No int } \\
\text { techni }\end{array}$ & & entions & s incluc & & & \\
\hline 28. Facilitate social comparison & 708 & 6 & .176 & 9642 & 55 & .232 & 0.71 & 446 & 5 & .845 & 7168 & 37 & .520 & $3.14^{* * *}$ \\
\hline 29. Plan social support/social change & 6144 & 32 & .258 & 4206 & 29 & .181 & $1.91^{*}$ & 3983 & 19 & .689 & 3631 & 23 & .388 & $6.36^{* *}$ \\
\hline 33. Prompt self-talk & 4717 & 22 & .232 & 5633 & 39 & .222 & 0.25 & 2854 & 11 & .751 & 4760 & 31 & .449 & $6.10^{* * *}$ \\
\hline 35. Relapse prevention/coping planning & 7209 & 37 & .244 & 3141 & 24 & .175 & 1.60 & 5067 & 24 & .656 & 2547 & 18 & .366 & $5.77^{* * *}$ \\
\hline 36. Stress Management/emotional control training & 4782 & 23 & .222 & 5568 & 38 & .184 & .96 & 2983 & 13 & .678 & 4631 & 29 & .414 & $5.41^{* * *}$ \\
\hline 37. Motivational interviewing & 389 & 4 & .223 & 9961 & 57 & .224 & 0.004 & 351 & 3 & .384 & 7263 & 39 & .513 & 1.15 \\
\hline 38. Time management & 4740 & 26 & .272 & 5610 & 35 & .192 & $2.01^{*}$ & 2386 & 16 & .553 & 5228 & 26 & .472 & 1.58 \\
\hline
\end{tabular}

techniques. This is something that needs further investigation in future research.

Furthermore, coding interventions was at times difficult due to the lack of precision and detail provided, as mentioned previously by other research groups [13]. Based on this, we were only able to code intervention techniques that were explicitly stated and strongly suggest that authors describe their interventions using terms from the behaviour change taxonomy in the future. Encouragingly, some researchers do this [26], which makes these type of reviews more accurate. Additionally, this review is concerned with summarising existing evidence, thereby generating new hypotheses for future research to test using experimental designs without such potential confounders. Lastly, more studies could have been included if the focus of this review had solely been on what BCTs increase physical activity [84]. However, a strength of this review is that it investigates both physical activity behaviour and self-efficacy which allows examination of theoretical determinants of physical 


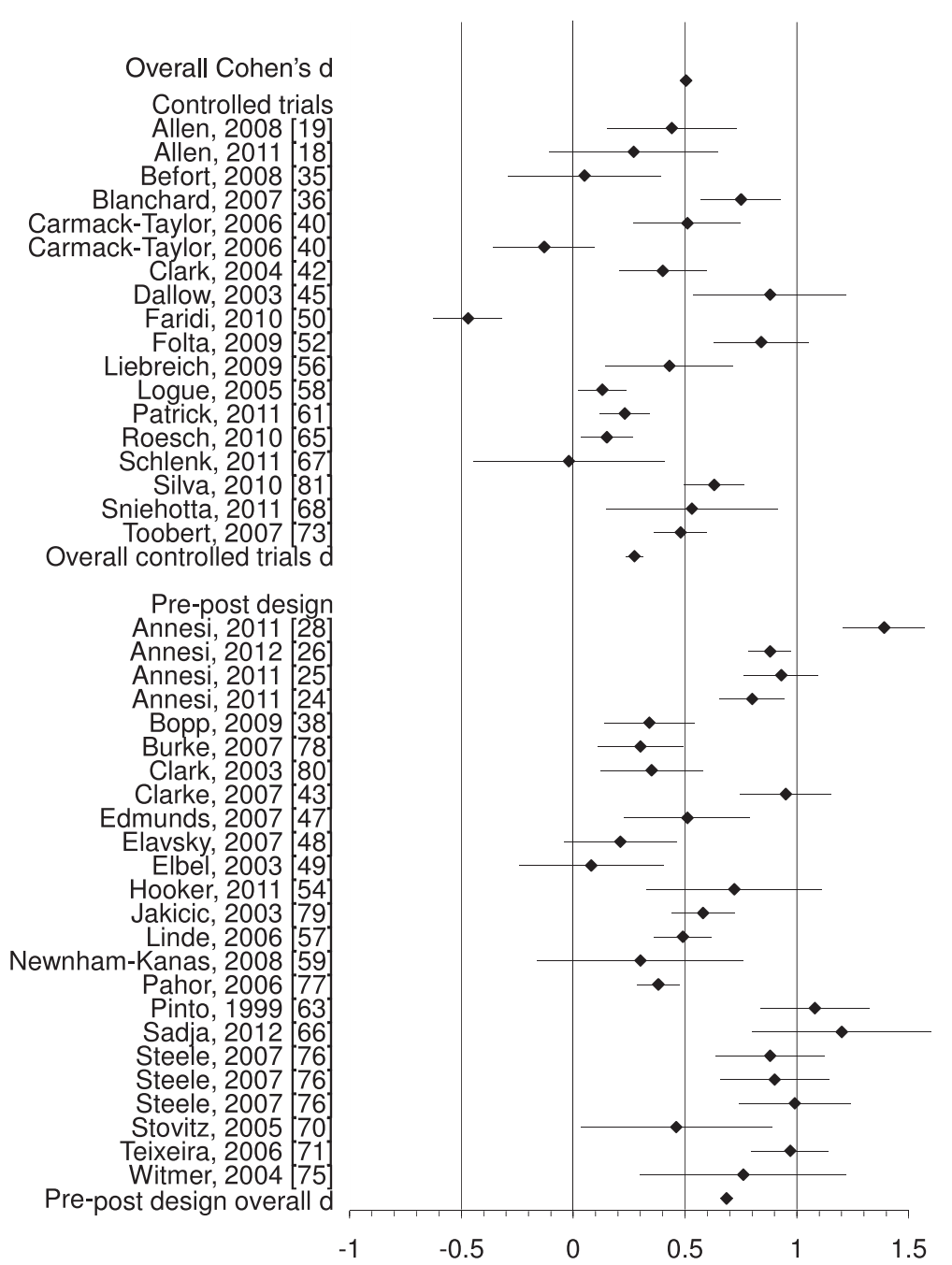

Figure 3 Forest plot showing physical activity effect sizes with $95 \% \mathrm{Cl}$ for each study, with studies ordered by research design.

activity in this population for whom physical activity should be a priority.

Which behaviour change techniques are associated with changes in self-efficacy for physical activity and physical activity behaviour in obese adults?

This review adds to the current literature by identifying which behaviour change techniques are associated with changes in self-efficacy and physical activity behaviour in an obese population. Previous reviews have identified BCTs effective in increasing this behaviour in other populations $[10,84]$ including obese individuals with additional risk factors [13]. Similarly, the previous review concerning which BCTs were associated with self-efficacy was conducted in an explicitly non-obese population [10].

Four behaviour change techniques were found to be associated with increased self-efficacy. These involved planning, prompting and practical skills. 'Action planning', involves planning where and when to act and in which situation and it seems likely that greater goal specification, i.e. knowing what to do where and when, may encourage the belief that engaging in physical activity is feasible. Similarly, time management is a practical skill that may increase individuals' belief that they can perform the behaviour by helping them feel they can better control potential obstacles. Neither of these BCTs however were associated with an increase in physical activity behaviour.

'Planning social support/social change' i.e. planning how to elicit social support for the target behaviour from other individuals may also help people feel more in control over the performance of physical activity by receiving greater practical support with obstacles such as family or work commitments. This is supported by an association between the presence of this $\mathrm{BCT}$ and behaviour. In addition, feeling supported may help this population cope with setbacks and relapses in physical activity. 
'Prompting self-monitoring of behavioural outcome', is defined as keeping a record of a specific outcome expected to be influenced by the behaviour change. In the two instances where this technique was identified, the outcome was weight loss [71,72]. It may be that self-monitoring one's weight and seeing a change in weight enhanced the individuals' feelings of being in control of physical activity, assuming they attributed any weight changes to their physical activity behaviour.

Two behaviour change techniques were associated with decreased self-efficacy; 'set graded tasks' and 'prompting generalisation of a target behaviour'. The first technique involves breaking down the behaviour into smaller, more achievable tasks, and is thought to enable the individual to build on small successes [12]. 'Prompting generalisation of a target behaviour' encourages the individual to try the behaviour in a different setting/situation, after first mastering it in one situation [12]. Both of these BCTs are based on the idea of breaking overall behaviour change into smaller achievable goals. However, to participants these BCTs may make the goals seem large, unmanageable and unattainable, and possibly seem to involve 'moving the goalposts'. Both of these techniques are used in skilled approaches such as cognitive behaviour therapy [85]. However, they may be poorly implemented within the studies included in this review, as many interventions were delivered by people such as fitness professionals that have not necessarily been trained to deliver behaviour change interventions. 'Prompting generalisation of a target behaviour' was the only technique that was associated with lower physical activity behaviour.

Overall, the most commonly used techniques were not found to be the techniques that may be most effective in increasing self-efficacy or physical activity (see Table 3 and 4). One of the potentially most effective BCTs was 'teach to use prompts/cues' and was used in only $16 \%$ of all physical activity comparisons. The second potentially most effective technique 'prompt practice' was identified in almost two thirds of all the interventions. It appears that the use of BCTs such as 'teach to use prompts/cues' and 'prompt practice' which involve prompting self regulation may potentially be particularly effective in helping obese individuals engage in physical activity. This finding is in line with a previous review of general physical activity interventions [84].

Another technique, 'prompt rewards contingent on effort or progress towards behaviour' involves the individual using self-reward or praise for attempts at achieving the behaviour. It may be that this population particularly needs encouragement as they try to change their physical activity behaviour. This is in line with the BCT 'plan social support/social change' which was associated with increased self-efficacy and physical activity.

\section{Are the same techniques which are associated with increased self-efficacy also associated with increased physical activity? Are they the same as in the review of non-obese adults?}

A negative and non-significant association (rho $=-0.18$ ) between changes in self-efficacy and changes in physical activity was observed across BCTs. Of the 28 techniques in the moderator analysis, only three BCTs were associated with the same result (increase or decrease in effect size for when the technique was present/not present) for both self-efficacy and physical activity behaviour. Two of these techniques, 'prompt self-monitoring of behavioural outcome' and 'plan social support/social change', were associated with a higher effect size estimate when the intervention included this technique. The third technique, 'prompting generalisation of a target behaviour', was associated with a lower effect size estimate when the interventions included this technique for both selfefficacy and physical activity behaviour. The majority of techniques included in moderator analyses (19/28) were associated with larger physical activity behaviour effect sizes but not self-efficacy effect sizes.

Taken together, these findings clearly suggest that there are many other routes apart from increasing self-efficacy that can help obese adults become more physically active. There were larger changes brought about in physical activity than for self-efficacy. Also, more BCT's were associated with increases in physical activity than increases in selfefficacy. The conclusion that self-efficacy is not the only route to behaviour change is in line with a recent review update which concluded that there is currently limited support for self-efficacy to act as a mediator of physical activity changes [86], in contrast to a commonly held view [8].

On the contrary, there may be something about an obese population that results in self-efficacy not being an important route to changing physical activity. The results of the present review stand in striking contrast to those of a previous review of non-obese adults, which found a strong and significant $(r=0.69)$ relationship between change in self-efficacy and change in physical activity behaviour.

Social cognitive theory does not propose that increasing self-efficacy will inevitably result in behaviour change [82]. The theory states that the effects of self-efficacy on behaviour will be moderated by outcome expectancies, i.e. beliefs that a particular behaviour will lead to a particular outcome. Where an individual believes that the behaviour will not lead to a valued outcome, self-efficacy will not motivate behaviour change. For example, an individual may believe they can drink fewer alcoholic drinks, but if they do not think the amount they are drinking is harmful, such self-efficacy will not result in less consumption. In terms of the present review, obese individuals may not believe that increasing their physical activity will lead to 
weight loss, which presumably would be a highly valued goal. There is evidence that the relationship between increased physical activity and weight loss is far from straightforward [87], so this would be a reasonable outcome expectancy for many obese people. Thus, this population may be convinced by an intervention that they can increase their physical activity, but if they were not convinced that this would result in the salient outcome of weight loss, it would not necessarily result in increased physical activity.

The techniques associated with increasing obese adults' self-efficacy and physical activity were generally not the same as the BCTs associated with such change in nonobese adults. For self-efficacy, the current review identified four techniques that were associated with increasing adults' self-efficacy where a review focusing on non-obese adults found three such techniques [10]. The only BCT that was found to be associated with increased self-efficacy in both populations was 'action planning' [10]. The current review identified $21 \mathrm{BCTs}$ that were associated with increased physical activity behaviour, whilst the review that focused on non-obese adults identified six BCTs [10]. Out of these six BCTs, four techniques were found to be associated with an increase in physical activity in both non-obese and obese adults ('provide information on consequences of behaviour in general,' 'prompt rewards contingent on effort or progress towards behaviour,' 'provide instruction on how to perform the behaviour' and 'facilitate social comparison'). These results highlight the importance of selecting appropriate $\mathrm{BCTs}$ for each population, and not assuming that BCTs will be uniformly effective, assuming these associations represent unique causal effects of each BCT.

\section{Implications and future directions}

If the associations identified in this review are shown to reflect causal effects of BCTs on physical activity, future interventions with this population should be able to bring about change in physical activity using approximately half the techniques examined: most techniques appear to be effective. However, greater change is likely with techniques concerned with self-regulation, replicating previous findings with a general population [84]. Furthermore, this review has identified some possibly effective yet seldom used BCTs such as 'teach to use prompts/cues'. We suggest future interventions include the BCTs that this review has identified as possibly effective, to maximize the intervention's potential to be effective. Unlike interventions with non-obese adults [10], it does not seem to be important to specifically target obese individuals' selfefficacy for physical activity in order to change their physical activity behaviour.

The present review has suggested a number of techniques are effective at increasing physical activity in obese individuals. Future research should test whether these associations reflect causal processes by using the present evidence base to develop interventions and then test their efficacy. Future research should also test whether increasing physical activity through increasing individuals' selfefficacy is the best route to increase physical activity behaviour in this population. The current findings suggest that there are alternative mechanisms for increasing obese individuals' physical activity behaviour, and there is a need for future research to identify these.

A strong test of the causal nature of the relationships identified in the present review, and a previous one involving non-obese adults [10] is also required. This would involve developing two interventions, each based on the BCTs identified as most associated with change in each population. A comparison would then be made of the relative efficacy of interventions which are 'matched' to the population for whom the intervention was developed, and 'mismatched' i.e. delivered to the other population.

\section{Conclusion}

In summary, this review and meta-analysis has identified several behaviour change techniques that are associated with increased self-efficacy and physical activity. Some of these techniques supported previous findings from a review with healthy and overweight adults [10], whilst other techniques may be effective in an obese population only. Thus, to develop effective physical activity interventions it may be important to consider tailoring intervention techniques to populations to a greater extent than is commonly the case.

\section{Endnotes}

${ }^{1}$ This search aimed to identify studies with obese people and older ( $>60$ years) adults. This was in line with objectives of the research commissioned by Macmillan Cancer Support [17]. Hence the number of publications retrieved reported here includes some that were retrieved with the older adults search criteria in mind.

${ }^{2}$ In this review the effect sizes for task and barrier self-efficacy respectively was not significantly different (task $d=0.26$, barrier $d=0.22, \mathrm{p}=0.23$ ).

\section{Appendix 1}

Scopus $(1960$ - 2011)

Terms in title, abstract or keyword.

Self-efficacy or Bandura or social cognitive theory.

OR

Theory of planned behaviour or theory of planned behavior or theory of reasoned action or perceived behavioural control or perceived behavioral control.

AND

Clinica* tria* or Randomised controlled tria* or Randomized controlled tria* or 
Blind or Controlled clinical trial or Mask or Random allocation or Double blind method or Intervention or Evaluation or Progra* or Follow-up study or Experiment. AND

Physical activity or exercise or fitness or exertion.

PsycInfo (1966-2011).

Search terms.

Self-efficacy or Bandura or social cognitive theory.

OR

Theory of planned behaviour or theory of planned behavior or theory of reasoned action or perceived behavioural control or perceived behavioral control.

AND

Clinica* tria* or Randomised controlled trial or Randomized controlled trial or.

Blind or Controlled clinical trial or Mask or Random allocation or Double blind method or Intervention or Evaluation or Progra* or Follow-up study.

AND

Physical activity or exercise or sport or fitness.

\section{Competing interests}

The authors declare that they have no competing interests.

\section{Authors' contributions}

DPF had the original idea for this review, which he developed with the input of EKO and AT. EKO and DPF developed the review protocol and EKO conducted the literature searches. EKO and LA were responsible for the title and abstract screening and full text assessment (with help from DPF). EKO, HF and SW coded the interventions, and did the data extraction together with LA. EKO conducted all statistical analysis with support from DPF and wrote the manuscript with help from DPF. All authors read and approved the final manuscript.

\section{Acknowledgements}

The authors would like to thank Debbie Shearring, research assistant, for her help with identifying papers for this review. They would also like to thank the following authors' for providing additional data used in this review: Nancy Allen, James Annesi, Cindy Carmack, Stephan Dombrowski, Kate Edwards, Steriani Elavsky, Russ Elbel, Everett Logue, Greg Norman, Falko Sniehotta, Pedro Teixeira and Deborah Toobert. This review was funded by Macmillan Cancer Support. We are grateful to Lynn Batehup of Macmillan Cancer Support for her support with this review. The funder was not involved in the design, data collection, analysis or interpretation of data, in the writing of the manuscript or in the decision to submit the manuscript for publication.

\section{Author details}

'Applied Research Centre in Health and Lifestyle Interventions, Coventry University, Priory Street, Coventry CV1 5FB, UK. ${ }^{2}$ School of Psychological Sciences, University of Manchester, Oxford Road, Manchester M13 9PL, UK.

Received: 14 September 2012 Accepted: 26 February 2013

Published: 3 March 2013

\section{References}

1. World Health Organization: Obesity and overweight. www.who.int/ mediacentre/factsheets/fs311/en.

2. Zaninotto P, Head J, Stamatakis E, Wardle H, Mindell J: Trends in obesity among adults in England from 1993 to 2004 by age and social class and projections of prevalence to 2012. J Epidemiol Community Health 2009, 63:140-146.

3. Mokdad AH, Ford ES, Bowman BA, Dietz WH, Vinicor F, Bales VS, Marks JS: Prevalence of obesity, diabetes, and obesity-related health risk factors, 2001. JAMA 2003, 289:76-79.
4. Kenchaiah S, Evans JC, Levy D, Wilson PWF, Benjamin EJ, Larson MG, Kannel WB, Vasan RS: Obesity and the risk of heart failure. N Engl J Med 2002, 347:305-313.

5. Luppino FS, de Wit LM, Bouvy PF, Stijnen T, Cuijpers P, Penninx BWJH, Zitman FG: Overweight, obesity, and depression: a systematic review and meta-analysis of longitudinal studies. Arch Gen Psychiatry 2010, 67:220-229.

6. Mokdad AH, Marks JS, Stroup DF, Gerberding JL: Actual causes of death in the United States, 2000. JAMA 2004, 291:1238-1245.

7. Jakicic JM, Otto AD: Treatment and prevention of obesity: what is the role of exercise? Nutr Rev 2006, 64:S57-S61.

8. Bauman AE, Reis RS, Sallis JF, Wells JC, Loos RJF, Martin BW: Correlates of physical activity: why are some people physically active and others not? Lancet 2012, 380:258-271.

9. Darker CD, French DP, Eves FF, Sniehotta FF: An intervention to promote walking amongst the general population based on an 'extended' theory of planned behaviour: a waiting list randomised controlled trial. Psychol Health 2010, 25:71-88.

10. Williams SL, French DP: What are the most effective intervention techniques for changing physical activity self-efficacy and physical activity behaviourand are they the same? Health Educ Res 2011, 26:308-322.

11. Ashford S, Edmunds J, French DP: What is the best way to change selfefficacy to promote lifestyle and recreational physical activity? A systematic review with meta-analysis. Br J Health Psychol 2010, 15:265-288.

12. Michie S, Ashford S, Sniehotta FF, Dombrowski SU, Bishop A, French DP: A refined taxonomy of behaviour change techniques to help people change their physical activity and healthy eating behaviours: the CALORE taxonomy. Psychol Health 2011, 26:1479-1498.

13. Dombrowski SU, Sniehotta FF, Avenell A, Johnston M, MacLennan G, Araújo-Soares V: Identifying active ingredients in complex behavioural interventions for obese adults with obesity-related co-morbidities or additional risk factors for co-morbidities: a systematic review. Health Psychol Rev 2012, 6:7-32.

14. Cohen J: A power primer. Psychol Bull 1992, 112:155-159.

15. Abraham C, Michie S: A taxonomy of behavior change techniques used in interventions. Health Psychol 2008, 27:379-387.

16. Schwarzer R: Statistics software for meta-analysis. http://userpage.fu-berlin. de/health/meta e.htm

17. French DP, Olander EK, Williams S, Fletcher H, Atkinson L, Turner A:; Building an evidence base for skills development training for cancer clinicians to support lifestyle behaviour change and self-management with cancer survivors; 2011. http://www.ncsi.org.uk/wp-content/uploads/Coventry-PAinterventions-FINAL-report-16dec2011PDF.pdf.

18. Allen N, Whittemore R, Melkus G: A continuous glucose monitoring and problem-solving intervention to change physical activity behavior in women with type 2 diabetes: a pilot study. Diabetes Technol Ther 2011, 13:1091-1099.

19. Allen NA, Fain JA, Braun B, Chipkin SR: Continuous glucose monitoring counseling improves physical activity behaviors of individuals with type 2 diabetes: a randomized clinical trial. Diabetes Res Clin Pract 2008, 80:371-379.

20. Annesi Jj: Relations of changes in exercise self-efficacy, physical self-concept, and body satisfaction with weight changes in obese white and African American women initiating a physical activity program. Ethn Dis 2007, 17:19-22.

21. Annesi JJ: Predictors of exercise-induced mood change during a 6month exercise and nutrition education program with obese women. Percept Mot Skills 2009, 109:931-940.

22. Annesi JJ: Dose-response and self-efficacy effects of an exercise program on vigor change in obese women. Am J Med Sci 2010, 339:127-132.

23. Annesi Jj: Relations of changes in self-regulatory efficacy and physical selfconcept with improvements in body satisfaction in obese women initiating exercise with cognitive-behavioral support. Body Image 2010, 7:356-359.

24. Annesi Jj: Self-regulatory skills usage strengthens the relations of selfefficacy for improved eating, exercise, and weight in the severely obese: toward an explanatory model. Behav Med 2011, 37:71-76.

25. Annesi JJ: Behaviorally supported exercise predicts weight loss in obese adults through improvements in mood, self-efficacy, and self-regulation, rather than by caloric expenditure. Perm J 2011, 15:23-27.

26. Annesi Jj: Supported exercise improves controlled eating and weight through its effects on psychosocial factors: extending a systematic research program toward treatment development. Perm J 2012, 16:7-18.

27. Annesi JJ, Gorjala S: Relations of self-regulation and self-efficacy for exercise and eating and BMI change: a field investigation. BioPsychoSoc Med 2010, 4:10. 
28. Annesi JJ, Marti CN: Path analysis of exercise treatment-induced changes in psychological factors leading to weight loss. Psychol Health 2011, 26:1081-1098

29. Annesi JJ, Unruh JL: Correlates of mood changes in obese women initiating a moderate exercise and nutrition information program. Psychol Rep 2006, 99:225-229.

30. Annesi JJ, Whitaker AC: Weight loss and psychologic gain in obese women-participants in a supported exercise intervention. Perm J 2008 12:36-45.

31. Annesi JJ, Whitaker AC: Psychological factors associated with weight loss in obese and severely obese women in a behavioral physical activity intervention. Health Educ Behav 2010, 37:593-606.

32. Annesi JJ, Whitaker AC: Psychological factors discriminating between successful and unsuccessful weight loss in a behavioral exercise and nutrition education treatment. Int J Behav Med 2010, 17:168-175.

33. Annesi JJ, Unruh JL, Whitaker AC: Relations of changes in self-efficacy, exercise attendance, mood, and perceived and actual physical changes in obese women: assessing treatment effects using tenets of self-efficacy theory. J Soc Behav Health Sci 2007, 1:72-85.

34. Annesi JJ, Unruh JL, Marti CN, Gorjala S, Tennant G: Effects of the coach approach intervention on adherence to exercise in obese women: assessing mediation of social cognitive theory factors. Res Q Exerc Sport 2011, 82:99-108.

35. Befort CA, Nollen N, Ellerbeck EF, Sullivan DK, Thomas JL, Ahluwalia JS: Motivational interviewing fails to improve outcomes of a behavioral weight loss program for obese African American women: a pilot randomized trial. J Behav Med 2008, 31:367-377.

36. Blanchard CM, Fortier M, Sweet S, O'Sullivan T, Hogg W, Reid RD, Sigal RJ: Explaining physical activity levels from a self-efficacy perspective: the physical activity counseling trial. Ann Behav Med 2007, 34:323-328.

37. Bolognesi M, Nigg CR, Massarini M, Lippke S: Reducing obesity indicators through brief physical activity counseling (PACE) in Italian primary care settings. Ann Behav Med 2006, 31:179-185.

38. Bopp M, Wilcox S, Laken M, Hooker SP, Parra-Medina D, Saunders R, Butler K, Fallon EA, McClorin L: 8 Steps to fitness: a faith-based, behavior change physical activity intervention for African Americans. J Phys Act Health 2009, 6:568-577

39. Burke V, Beilin $\sqcup$, Cutt HE, Mansour J, Mori TA: Moderators and mediators of behaviour change in a lifestyle program for treated hypertensives: a randomized controlled trial (ADAPT). Health Educ Res 2008, 23:583-591.

40. Carmack Taylor CL, Demoor C, Smith MA, Dunn AL, Basen-Engquist K, Nielsen I, Pettaway C, Sellin R, Massey P, Gritz ER: Active for life after cancer: a randomized trial examining a lifestyle physical activity program for prostate cancer patients. Psychooncol 2006, 15:847-862.

41. Clark DO, Stump TE, Damush TM: Outcomes of an exercise program for older women recruited through primary care. J Aging Health 2003, 15:567-585.

42. Clark M, Hampson SE, Avery L, Simpson R: Effects of a brief tailored intervention on the process and predictors of lifestyle behaviour change in patients with type 2 diabetes. Psychol Health Med 2004, 9:440-449.

43. Clarke KK, Freeland-Graves J, Klohe-Lehman DM, Milani TJ, Nuss HJ, Laffrey S: Promotion of physical activity in low-income mothers using pedometers. J Am Diet Assoc 2007, 107:962-967.

44. Daley LK, Fish AF, Frid DJ, Mitchell GL: Stage-specific education/counseling intervention in women with elevated blood pressure. Prog Cardiovasc Nurs 2009, 24:45-52

45. Dallow CB, Anderson J: Using self-efficacy and a transtheoretical model to develop a physical activity intervention for obese women. Am J Health Promot 2003, 17:373-381.

46. David P, Buckworth J, Pennell ML, Katz ML, DeGraffinreid CR, Paskett ED: A walking intervention for postmenopausal women using mobile phones and interactive voice response. J Telemed Telecare 2012, 18:20-25.

47. Edmunds J, Ntoumanis N, Duda JL: Adherence and well-being in overweight and obese patients referred to an exercise on prescription scheme: a selfdetermination theory perspective. Psychol Sport Exerc 2007, 8:722-740.

48. Elavsky S, McAuley E: Exercise and self-esteem in menopausal women: a randomized controlled trial involving walking and yoga. Am J Health Promot 2007, 22:83-92.

49. Elbel R, Aldana S, Bloswick D, Lyon JL: A pilot study evaluating a peer led and professional led physical activity intervention with blue-collar employees. Work 2003, 21:199-210

50. Faridi Z, Shuval K, Njike VY, Katz JA, Jennings G, Williams M, Katz DL: Partners reducing effects of diabetes (PREDICT): a diabetes prevention physical activity and dietary intervention through African-American churches. Health Educ Res 2010, 25:306-315.

51. Focht BC, Rejeski WJ, Ambrosius WT, Katula JA, Messier SP: Exercise, selfefficacy, and mobility performance in overweight and obese older adults with knee osteoarthritis. Arthritis Rheum 2005, 53:659-665.

52. Folta SC, Lichtenstein AH, Seguin RA, Goldberg JP, Kuder JF, Nelson ME: The strongwomen-healthy hearts program: reducing cardiovascular disease risk factors in rural sedentary, overweight, and obese midlife and older women. Am J Public Health 2009, 99:1271-1277.

53. Gallagher Kl, Jakicic JM, Napolitano MA, Marcus BH: Psychosocial factors related to physical activity and weight loss in overweight women. Med Sci Sports Exerc 2006, 38:971-980.

54. Hooker SP, Harmon B, Burroughs EL, Rheaume CE, Wilcox S: Exploring the feasibility of a physical activity intervention for midlife African American men. Health Educ Res 2011, 26:732-738.

55. Halbert CH, Bellamy S, Bowman M, Briggs V, Delmoor E, Purnell J, Rogers R Weathers B, Kumanyika S: Effects of integrated risk counseling for cancer and cardiovascular disease in African Americans. J Natl Med Assoc 2010, 102:396-402.

56. Liebreich T, Plotnikoff RC, Courneya KS, Boulé N: Diabetes NetPLAY: a physical activity website and linked email counselling randomized intervention for individuals with type 2 diabetes. Intl J Behav Nutr Phys Act 2009, 6:18

57. Linde JA, Rothman AJ, Baldwin AS, Jeffery RW: The impact of self-efficacy on behavior change and weight change among overweight participants in a weight loss trial. Health Psychol 2006, 25:282-291.

58. Logue E, Sutton K, Jarjoura D, Smucker W, Baughman K, Capers C: Transtheoretical model-chronic disease care for obesity in primary care: a randomized trial. Obes Res 2005, 13:917-927.

59. Newnham-Kanas C, Irwin JD, Morrow D: Co-active life coaching as a treatment for adults with obesity. Int/ J Evidence Based Coach Mentoring 2008, 6:1-12.

60. Palmeira AL, Teixeira PJ, Branco TL, Martins SS, Minderico CS, Barata JT, Serpa SO, Sardinha LB: Predicting short-term weight loss using four leading health behavior change theories. Int J Behav Nutr Phys Act 2007, 4.

61. Patrick K, Calfas KJ, Norman GJ, Rosenberg D, Zabinski MF, Sallis JF, Rock CL, Dillon LW: Outcomes of a 12-month web-based intervention for overweight and obese men. Ann Behav Med 2011, 42:391-401.

62. Perry CK, Rosenfeld AG, Bennett JA, Potempa K: Promoting walking in rural women through motivational interviewing and group support. J Cardiovasc Nurs 2007, 22:304-312.

63. Pinto BM, Clark MM, Cruess DG, Szymanski L, Pera V: Changes in selfefficacy and decisional balance for exercise among obese women in a weight management program. Obes Res 1999, 7:288-292.

64. Rejeski WJ, King AC, Katula JA, Kritchevsky S, Miller ME, Walkup MP, Glynn NW, Pahor M: Physical activity in prefrail older adults: confidence and satisfaction related to physical function. J Gerontol B Psychol Sci Soc Sci 2008, 63B:P19-P26.

65. Roesch SC, Norman GJ, Villodas F, Sallis JF, Patrick K: Intervention-mediated effects for adult physical activity: a latent growth curve analysis. Soc Sci Med 2010, 71:494-501.

66. Sadja J, Tomfohr L, Jimenez JA, Edwards KM, Rock CL, Calfas K, Mills PJ: Higher physical fatigue predicts adherence to a 12-week exercise intervention in women with elevated blood pressure. Health Psychol 2012, 31:156-163.

67. Schlenk EA, Lias JL, Sereika SM, Dunbar-Jacob J, Kwoh CK: Improving physical activity and function in overweight and obese older adults with osteoarthritis of the knee: a feasibility study. Rehabil Nurs 2011, 36:32-42.

68. Sniehotta FF, Dombrowski SU, Avenell A, Johnston M, McDonald S, Murchie $P$, Ramsay CR, Robertson K, Araujo-Soares V: Randomised controlled feasibility trial of an evidence-informed behavioural intervention for obese adults with additional risk factors. PLoS One 2011, 6:e23040.

69. Steele RM, Mummery WK, Dwyer T: A comparison of face-to-face or internet-delivered physical activity intervention on targeted determinants. Health Educ Behav 2009, 36:1051-1064.

70. Stovitz SD, VanWormer JJ, Center BA, Bremer KL: Pedometers as a means to increase ambulatory activity for patients seen at a family medicine clinic. J Am Board Fam Pract 2005, 18:335-343.

71. Teixeira PJ, Going SB, Houtkooper LB, Cussler EC, Metcalfe LL, Blew RM, Sardinha LB, Lohman TG: Exercise motivation, eating, and body image variables as predictors of weight control. Med Sci Sports Exerc 2006, 38:179-188. 
72. Teixeira PJ, Silva MN, Coutinho SR, Palmeira AL, Mata J, Vieira PN, Carraça EV, Santos TC, Sardinha LB: Mediators of weight loss and weight loss maintenance in middle-aged women. Obesity 2010, 18:725-735.

73. Toobert DJ, Glasgow RE, Strycker LA, Barrera M Jr, Ritzwoller DP, Weidner G: Long-term effects of the mediterranean lifestyle program: a randomized clinical trial for postmenopausal women with type 2 diabetes. Int J Behav Nutr Phys Act 2007, 4:1.

74. Wang C, Schmid CH, Hibberd PL, Kalish R, Roubenoff R, Rones R, McAlindon $\mathrm{T}$ : Tai $C$ i is effective in treating knee osteoarthritis: a randomized controlled trial. Arthritis Rheum 2009, 61:1545-1553.

75. Witmer JM, Hensel MR, Holck PS, Ammerman AS, Will JC: Heart disease prevention for Alaska native women: a review of pilot study findings. J Womens Health (Larchmt) 2004, 13:569-578.

76. Steele R, Mummery WK, Dwyer T: Using the Internet to promote physical activity: a randomized trial of intervention delivery modes. J Phys Act Health 2007, 4:245-260.

77. Pahor M, Blair SN, Espeland M, Fielding R, Gill TM, Guralnik JM, Hadley EC, King AC, Kritchevsky SB, Maraldi C, et al: Effects of a physical activity intervention on measures of physical performance: results of the lifestyle interventions and independence for elders pilot (LIFE-P) study. J Gerontol A Biol Sci Med Sci 2006, 61:1157-1165.

78. Burke V, Beilin L, Cutt HE, Mansour J, Williams A, Mori TA: A lifestyle program for treated hypertensives improved health-related behaviors and cardiovascular risk factors, a randomized controlled trial. J Clin Epidemiol 2007, 60:133-141.

79. Jakicic JM, Marcus BH, Gallagher Kl, Napolitano M, Lang W: Effect of exercise duration and intensity on weight loss in overweight, sedentary women: a randomized trial. JAMA 2003, 290:1323-1330.

80. Clark M, Hampson SE, Avery L, Simpson R: Effects of a tailored lifestyle self-management intervention in patients with type 2 diabetes. Br J Health Psychol 2004, 9:365-379.

81. Silva MN, Vieira PN, Coutinho SR, Minderico CS, Matos MG, Sardinha LB, Teixeira PJ: Using self-determination theory to promote physical activity and weight control: a randomized controlled trial in women. J Behav Med 2010, 33:110-122.

82. Bandura A: Self-efficacy: the exercise of control. New York: W.H. Freeman and Company; 1997.

83. Rosenthal R: Meta-analytic procedures for social research. Beverly Hills, CA: Sage; 1984.

84. Michie S, Abraham C, Whittington C, McAteer J, Gupta S: Effective techniques in healthy eating and physical activity interventions: a metaregression. Health Psychol 2009, 28:690-701.

85. Beck AT, Rush AJ, Shaw BF, Emery G: Cognitive therapy of depression. New York: The Guilford Press; 1987.

86. Rhodes RE, Pfaeffli LA: Mediators of physical activity behaviour change among adult non-clinical populations: a review update. Int I Behav Nutr Phys Act 2010, 7:37.

87. Ebersole K, Dugas L, Durazo-Arvizu RA, Adeyemo AA, Tayo BO, Omotade OO, Brieger W, Schoeller DA, Cooper RS, Luke A: Energy expenditure and adiposity in Nigerian and African American women. Obesity 2008, 16:2148-2154.

doi:10.1186/1479-5868-10-29

Cite this article as: Olander et al.: What are the most effective techniques in changing obese individuals' physical activity self-efficacy and behaviour: a systematic review and meta-analysis. International Journal of Behavioral Nutrition and Physical Activity 2013 10:29.

\section{Submit your next manuscript to BioMed Central and take full advantage of:}

- Convenient online submission

- Thorough peer review

- No space constraints or color figure charges

- Immediate publication on acceptance

- Inclusion in PubMed, CAS, Scopus and Google Scholar

- Research which is freely available for redistribution 